\title{
Study of Connotation: Kent and Rosanoff's Test of Association of Words and Ideas in a Creative Perspective
}

\author{
Euphrosyne Efthimiadou ${ }^{1}$ \\ ${ }^{1}$ Department of Aeronautical Sciences, Division of Leadership-Command, Humanities and Physiology, Hellenic \\ Air Force Academy, Dekeleia Air Force Base, Attica, Greece \\ Correspondence: Euphrosyne Efthimiadou, Department of Aeronautical Sciences, Division of \\ Leadership-Command, Humanities and Physiology, Hellenic Air Force Academy, Dekeleia Air Force Base, \\ Attica, Greece.
}

Received: January 7, 2017

Accepted: January 31, 2017

Online Published: February 20, 2017

doi:10.20849/aes.v2i1.111

URL: http://dx.doi.org/10.20849/aes.v2i1.111

\begin{abstract}
The test of association of words and ideas proposed by Kent and Rosanoff, may be designed as a creative technique to study the mental operations selected by a population. This test has been carried out with two groups of Greek pupils in order to study the gap of the interpretations proposed from the term "watch", an object that is not found only in school, but that reminds to the rhythm of school life and by extension, to the employment of time regulating daily life. The test of association of words and ideas is of interest if one examines, on the one hand, the total of connotations produced by the students and if one compares, on the other hand, the statements of the two groups in relation to their level of studies and to their ability to combine unexpected ideas. The study of connotation for the study of the mechanism of the association of words and ideas from the inducing object of the watch can be used to draw conclusions on the type of mental operations carried out by the two groups of participants in distinguished social and personal areas. Finally, the scope of the interpretation of the inducing object suggested always remains open. Thus, the territory of the associated ideas remains unconquered and reveals the psychology and the inventiveness of the participants.
\end{abstract}

Keywords: Kent and Rosanoff's test of association of words and ideas, creative perspective, mental operations, combines unexpected and original ideas

\section{Introduction}

Two American researchers, Kent, G.H. and Rosanoff, A. J., published a study in psychology entitled "A Study of association in insanity, I, Association in normal subjects" (1910), which aimed to find unexpected and original associations from one hundred (100) words of a proposed list, in view to studying the categories of associations of ideas triggered by the words induced.

Nowadays, the test of association of words and ideas proposed by Kent and Rosanoff, may be designed as a creative technique to study the mental operations selected by a population. "In particular, humans have a mechanism for representing mental representations and for drawing intuitive inferences about them. This theory of mind mechanism is essential to our understanding of others and of ourselves (Leslie 1987; Premack \& Woodruff 1978). Humans also have a mechanism for representing verbal representations and for drawing intuitive inferences about them. This pragmatic mechanism is essential to our understanding of communicated meaning in context (Grice 1975; Sperber \& Wilson 2002)." (Mercier, Sperber, 2011).

This test has been carried out with two groups of Greek pupils in order to study the gap of the interpretations proposed from the term "watch", an object that is not found only in school, but that reminds to the rhythm of school life and by extension, to the employment of time regulating daily life. The students have been asked to list in a three (3) minutes time limit, the maximum of words associated with the chosen inducing object.

Once the test was accomplished, it was decided to process the collected material. At first, the words induced were classified in categories and their frequency was studied. Afterwards the process of the flow of ideas was put in trial and finally, personal comments were expressed, in order to analyze the results of the responses collected. 


\section{The Classification of Words Induced in Categories and Their Frequency}

The test of association of words and ideas is of interest if one examines, on the one hand, the total of connotations produced by the students and if one compares, on the other hand, the statements of the two groups in relation to their level of studies and to their ability to combine unexpected ideas. "In reviewing existing theories of creativity, 4 mental operations seem to account for creative cognition: application, analogy, combination, and abstraction" (Welling, 2010).

The statistical survey of twenty (20) students produced eighty two (82) different words for the term "watch". On this point, it is significant that the students exceeded the limited data and cited exact or rare terms. The answers cover fields ranging from the description of the exterior of the inducing object to its function in daily life and even more, of its symbolism. Beyond the lexical field restricting the word "watch", the cited answers attest to imaginary (see Table 1, Classification of words induced in categories, Group A \& Group B).

Table 1. Classification of words induced in categories, Group A \& Group B

\section{THE PARTS OF THE WATCH}

\begin{tabular}{|c|}
\hline A.IDENTIFICATION \\
\hline GROUP A \\
\hline $\begin{array}{l}\text { Wrist watch (4 frequencies), hand ( } 1 \text { frequency), hands ( } 4 \text { frequencies), winder (1 frequency), number (1 } \\
\text { frequency), numbers (4 frequencies) }\end{array}$ \\
\hline GROUP B \\
\hline $\begin{array}{l}\text { wrist watch ( } 1 \text { frequency), hand( } 1 \text { frequency), hands( } 4 \text { frequencies), } 3 \text { hands ( } 1 \text { frequency), numbers ( } 3 \\
\text { frequencies), glass ( } 2 \text { frequencies), glass and metal ( } 1 \text { frequency), battery ( } 1 \text { frequency), phosphorus ( } 1 \\
\text { frequency), small light( } 1 \text { frequency), diamonds ( } 1 \text { frequency })\end{array}$ \\
\hline B. DECODING \\
\hline GROUP A \\
\hline color (3 frequencies) \\
\hline GROUP B \\
\hline colors ( 1 frequency), leather ( 3 frequencies), plastic ( 2 frequencies) \\
\hline 2. THE CIRCULAR SHAPE \\
\hline IDENTIFICATION \\
\hline GROUP A \\
\hline circle (3 frequencies), ball ( 1 frequency), head ( 1 frequency) \\
\hline GROUP B \\
\hline $\begin{array}{c}\text { circle ( } 1 \text { frequency), roundabout ( } 1 \text { frequency), head ( } 1 \text { frequency), brioche ( } 1 \text { frequency), dial phone ( } 1 \\
\text { frequency), round shape ( } 1 \text { frequency) }\end{array}$ \\
\hline 3. THE TYPES OF WATCH \\
\hline A.IDENTIFICATION \\
\hline GROUP A \\
\hline Nothing \\
\hline GROUP B \\
\hline clock ( 1 frequency), watch ( 1 frequency), alarm clock ( 1 frequency) \\
\hline
\end{tabular}




\section{B. DECODING}

\section{GROUP A \\ Nothing \\ GROUP B}

Big - Ben in London (1 frequency), sand glass (1 frequency), sundial (1 frequency)

4. THE TIME

\begin{tabular}{|c|}
\hline A.IDENTIFICATION \\
\hline GROUP A \\
\hline hour (7 frequencies), minutes (2 frequencies), seconds (2 frequencies) \\
\hline GROUP B \\
\hline hour (6 frequencies), minutes (4 frequencies), seconds (5 frequencies) \\
\hline B. TEMPORAL INFERENCE \\
\hline
\end{tabular}

\section{GROUP A}

Time (1 frequency)

\section{GROUP B}

time ( 1 frequency), 24 hours ( 1 frequency), day ( 3 frequencies),

date (2 frequencies), month (2 frequencies), decade (1 frequency),

millenium (1 frequency), century (1 fréquence), the next day (1 frequency), the day after tomorrow (1 frequency), the morning ( 1 frequency),the evening ( 1 frequency), the afternoon ( 1 frequency)

\section{DECODING}

GROUP A

work (1 frequency), meal (1 frequency), medicine (1 frequency)

\section{GROUP B}

school (1 frequency), course (1 frequency)

\section{THE PERSON}

\begin{tabular}{|c|}
\hline DECODING \\
\hline GROUP A \\
\hline Nothing \\
GROUP B \\
\hline 6.THE HUMAN BODY \\
\hline INFERENCE \\
\hline GROUP A \\
\hline Hand (3 frequencies) \\
\hline GROUP B \\
\hline hand (3 frequencies), finger (1 frequency), wrist (1 frequency) \\
\hline
\end{tabular}




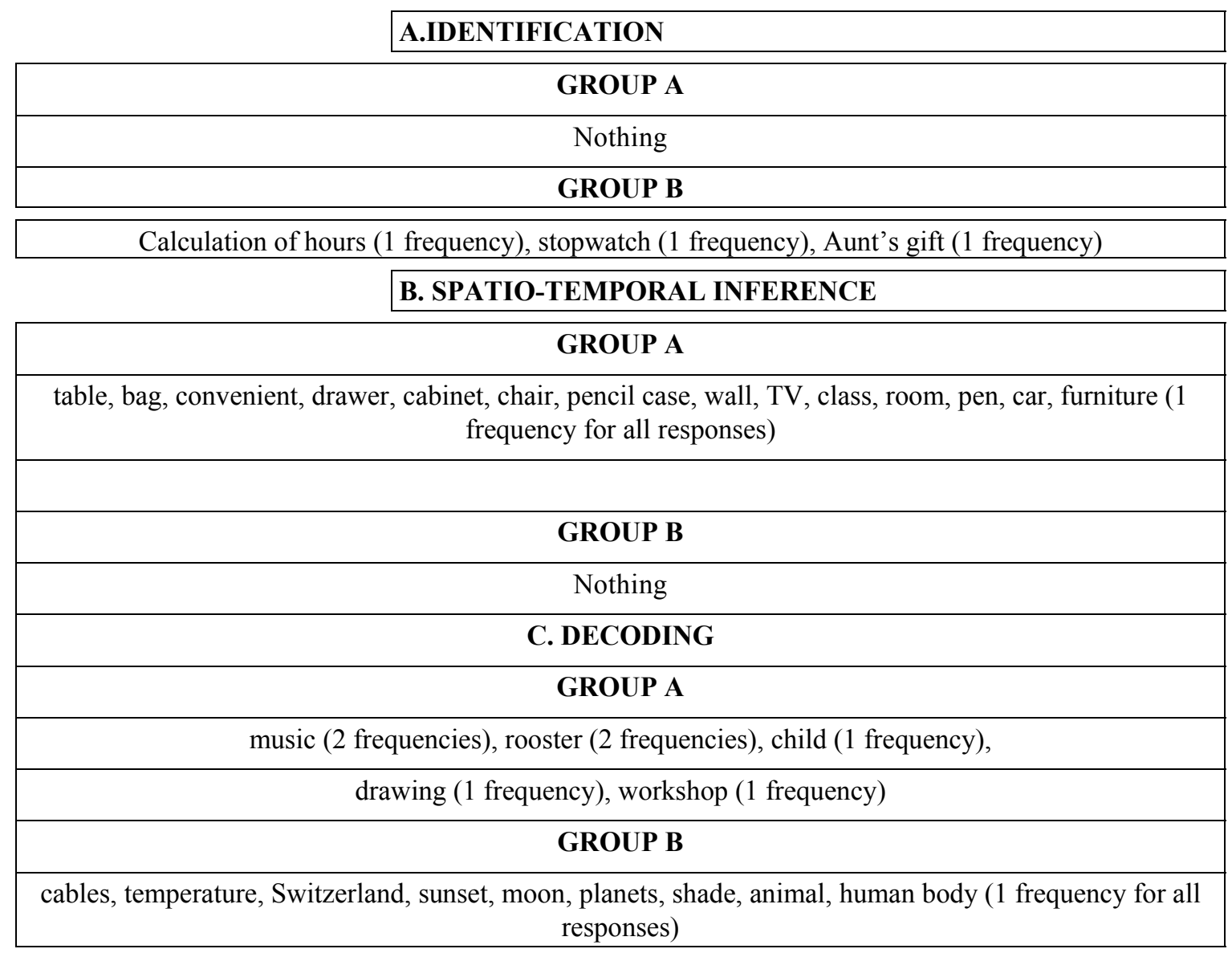

\subsection{The Mental Operations: a. Identification, b. Inference, c. Decoding}

Induced words classified into categories provide information about the parts of the watch, in response to an operation of identification (wristwatch, hands, winder, figures, metal, glass, battery, phosphorus, small light) or decoding (leather, plastic, colors). On the other hand, the circular form reminded "the circle", "the ball", "head", "the roundabout", 'brioche', "phone dial", "round", triggering an identification by metaphor. On the types of watch, learners respond by identification (clock, watch, alarm clock) or decoding (Big Ben in London, the sandglass, the sundial). Moreover, the watch indicates the passing of time and the operation of identification (hours, minutes, seconds) gives rise to inferences of temporal (time, 24 hours, day, date, month, Millennium, century, decade, the next day, the day after tomorrow, morning, afternoon, evening) and decoding operations (work, meal, medicine, school, course). Finally, students perform a decoding to designate a person (watchmaker) and inference to highlight parts of the human body where you wear the watch (hand, finger, wrist).

Moreover, a strong discrepancy occurs between the two groups: one tends to conformity by the choice of responses, while the other gives evidence of creativity and inventiveness. In the first group, there is abundance on the parts of the watch and the temporal references (hour, minutes, seconds). However, in the second group, students cite rare words/expressions. They proceed with identification (calculation of hours, watches, stopwatch, a gift from an aunt, by spatio-temporal inference (table, bag, convenient, drawer, cabinet, chair, pencil case, wall, $\mathrm{TV}$, class, room, pen, car, furniture) or by decoding (music, rooster, child, drawing, workshop, cables, temperature, Switzerland, sunset, moon, planets, shade, animal, human body).

\subsection{Social and Personal Areas}

The study of the frequency of the inducing term "watch" allows to distinguish between social and personal areas. "The relationship between a representation and the object it represents can be of two kinds: It can be based on resemblance or on truth. Any object in the world can, under appropriate conditions, be used as a representation of some other object that it resemble" (Sperber,Wilson 1987). Concerning social areas, students in both groups refer to the parts of the watch (wristwatch, hands, numbers, colors), the circular shape (circle, head), the time and the human body (hand). The creative group is distinguished by its ability and its knowledge of the world. In this case, 
the personal areas include types of watches, the watchmaker, and the individual areas offer semantic extensions remarkable for their inventiveness, considering the shortness of time.

\section{The Process of the Sequence of the Ideas}

The mechanism of the association of words and ideas resembles a trellis. Semantic landslides take place according to the line of similarities, adjacencies or contrasts. "Aristotle, Plato's student, was the first to observe that "association" among ideas facilitated understanding and recall. He believed that comprehension was aided by contiguity, succession, similarity and contrast. » (Grinder, 1989). In this context, it is important to observe the variable sequence of ideas and to clarify the domain to which they belong.

\subsection{Defining Divergences by Similarity, by Contiguity, by Contrast}

The leaps provided by students present verbal fluency. It is undeniable that most of them refer to the context and give elements on the temporal indication and the parts of the watch.

As regards to the first group, half of the students perceive by similarity, place "watch" in relationship with time and their thinking proceeds by contiguity to the description of the exterior of the inducing object (No. 3, 4, 5, 6, 8: Time), (No. 3, 5, 6, 7, 8, 10: description of the watch). Just one pupil makes a single reference to the moments of the day and by synecdoche, refers to the "hand". Moreover, 3 students out of 10, perceive by similarity a relationship with the circular shape (No. 1, 9,10). Also, two learners are adhered to their ideas of alternation and implement the mechanism of adjacency (rooster, circle, music) and proceed, by the suite, the first one by contiguity (rooster) and the second one by similarity (time). In addition, 2 students' tracks of ideas out of 10 are based on adjacency. The first one begins with a report of adjacency (hand), and then continues with a report of similarity (wristwatch) and arrives by contiguity to list the parts of the body where one can put on a watch, making reference to the lively "child". The reconciliations of the second one rely at first on a report of similarity (hands, hour) and then of adjacency (hand, wall) to return to a similar idea (wristwatch) and start afresh by the channel of the mechanism of adjacency: he refers then, as the first one, to parts where one can find a watch (bag, television, class, house, pen, car, furniture). Among these objects, he alludes to the drawing and the workshop. Finally, in a remarkable way, he is led by a circular movement to the introduced word "watch" (see Table 2, List of words induced in Group A).

Table 2. List of words induced in Group A

1. circle, music, hour, rooster

2. hand, wristwatch, table, bag, child, convenient, drawer, wardrobe, chair, pencil case

3. time, time, work, hand, meal, medicine, wristwatch, hand

4. hands, time, hand, wall, wristwatch, bag, television, class, house, drawing, workshop, pen, car, furniture, watch

5. hour, minutes, numbers, hands, color

6. hour, minutes, seconds, winder, numbers, color

7. figures, hands, wristwatch

8. time, seconds, head, numbers

9. ball, rooster, circle, music, hour

10. circle, number, color, needles

Concerning the second group, the initiative of students highlights their psychology: they deviate from the Sociology of the community. They provide unexpected responses that distinguish them from the common spirit. 3 students out of 10 proceeding by similarity refer to both the time and the material components of the watch (No. 8, 9, 10). More specifically, the two students reach different conclusions by contiguity: for the first one, the wristwatch reminds him of "leather" and, as a result, "animal" - a living creature, for the second one, the temporal indication "minutes" leads him to specify his daily occupations "school", "course". Two other students report by synecdoche parts of the human body (no. 2: human body, finger, hand - No. 6: hand, wrist) and this mechanism of adjacency gives rise to the establishment of a similarity by the indication of time (no. 2: hour, 
minutes, seconds) and the description of the inducing object (no. 5: three hands, glass and metal, No. 6: figures, colors). However, this last pupil enriches the list of words produced referring by contiguity at different periods of the day and the spatial extent of the universe (no. 6: moon, planets). Moreover, two students are still engaged in an association between inanimate objects and humans by their reference to the person, the watchmaker (No. 5, 7) If they begin by contiguity, they continue to outline by similarity the types of watches. It still happens that 3 out of 10 students move in a single thematic unity. The first one (No. 1), by a mechanism of similarity, names objects with a circular form. The second one (No. 3) begins to cite by similarity "the hour" and three words later "the seconds", but for all the rest words cited, he proceeds by adjacency. All cited words which he reports belong to the semantic field of Time. Finally, the last one (No. 4) begins to cite by similarity to a external description of the watches and employs a mainly specialised vocabulary. He refers by contiguity to "cables" and the "stopwatch" for a start and, by contiguity again, to two temporal indications: "date", "day". He finally introduces a parallel notion, that of "temperature" (see Table 3, List of words induced in Group B).

Table 3. List of words induced in Group B

\begin{tabular}{|l|}
\hline 1. head, circle, roundabout, brioche, phone dial \\
\hline 2. wristwatch, human body, finger, hand, hours, minutes, seconds \\
\hline 3. hour, time, day, seconds, school, months, decade, millennium, century \\
\hline 4. battery, cables, plastic, glass, hands, phosphorus, stopwatch, small light, date, day, temperature \\
\hline $\begin{array}{l}\text { 5. watchmaker, hand, Switzerland, Big-Ben in London, round form, hour, date, day, month, } 3 \text { hands, glass and } \\
\text { metal }\end{array}$ \\
\hline $\begin{array}{l}\text { 6. hand, hands, wrist, seconds, minutes, the next day, the day after tomorrow, morning, evening, afternoon, } \\
\text { sunset, moon, planets, leather, numbers, colors }\end{array}$ \\
\hline $\begin{array}{l}\text { 7. diamonds, leather, plastic, glass, watchmaker, the aunt's gift, sandglass, sundial, shade, calculation of hours, } \\
\text { alarm }\end{array}$ \\
\hline 8. hands, hour, seconds, minutes, numbers \\
\hline 9. time, hands, figures, 24 hours, wristwatch, leather, leather, animal \\
\hline 10. Hour, hands, seconds, minutes, school, course \\
\hline
\end{tabular}

\subsection{Domain of Science or Rhetorics?}

Therefore, the same inducing object causes sequences of enriching ideas. Half of the students' responses are related to the scientific field. The interpretations of certain ones emphasize their rhetoric competence: they refer to the circular shape, to symbols (rooster, music) or in places where the inducing object is located. So, the students' responses present a certain degree of variety. Even if most of them quote words belonging to the scientific domain, each student completes his idea of departure by introducing terms related to poetic creation. Furthermore, the utterance of their subsidiary ideas inspires the imagination by the surprise that it generates.

\section{Personal Remarks}

Once Kent and Rosanoff's test of association of words and ideas designed as a technique of creativity is completed, we can arrive to some interesting findings.

Even if the watch, while not a school object, rules in reality the pace of school life, students' interpretations exceed the given reality to refer rather to the generic notions of usage. First of all, pupils employ a technical vocabulary to describe the inducing object. It is significant that two students of the first group refer to a "hand" or to a "figure". On the other hand, the members of the second group have a more precise knowledge of the world. Some of them give scientific details on the components of the watch and complete their information by naming the material of which the watch is manufactured. In a broader sense, they refer to a round shape to which they exclusively identify the watch. Moreover, it is interesting to note that two students bring only specific information on the history of existing watches.

In addition, the watch is used to indicate the hour and different times of the day. Almost all students emphasize the role of the watch as such, without any reference to its applications in the daily school life. Also, two students 
of the first group list the places where you can put the inducing object and introduced a spatial reference as well. Finally, a small number of them both humanizes the object referring to the "hand" which bears the watch and, in one case through "Leather" one recalls the animal. Here, the watch, an inanimate object, is put in relationship with a living being. However, just one pupil quotes "the human body". On this point, a parallelism is established between the mechanism of the watch and that of the human body. The vibration, the sound and the regular clockwork movement - tic-tac - are assimilated to the human heart, an organ gifted with pulsations. Finally, it should be noted that no participant proceeded to associations of ideas by contrast.

Certainly, the participants of the second group possess an experience of the world and offer a variety of enriching interpretations in relation to the members of the first group whose collected responses fall to the same semantic field in most of the cases.

\section{Conclusion}

The application of the Kent and Rosanoff's test of association of words and ideas in a creative perspective opens the field of the interpretation of the responses collected by highlighting the mental operations of the interviewees. Even if, in the first group, the participants provide a plurality of responses characterized by identification, in the second group, the students' answers tend to be characterized by their variety, not only by identification but especially by inference and even by decoding. For this reason, the study of connotation through the study of the mechanism of the association of words and ideas from the inducing object of the watch can be used to draw conclusions on the type of mental operations carried out by the two groups of participants in distinguished social and personal areas. It is still significant that the types of passages from the inducing word to the words inducted is realized by similarity in the first group of people surveyed. Yet, in the second group, the follow up of one idea to the next sometimes rises unexpected interpretations. It sometimes happens to locate terms orienting to the domain of science and rhetorics. Moreover, it is observed that the sequence of ideas by contiguity leads to original associations, emphasizing the appeal to the creative imagination. Finally, the scope of the interpretation of the inducing object suggested always remains open. Thus, the territory of the associated ideas remains unconquered and reveals the psychology and the inventiveness of the participants. Concluding, it is necessary to point out the importance of this research concerning the degree of creativity that emerges from some participants' answers who react not only by analogy but also by divergence, sometimes achieving some original views by their inventiveness.

\section{References}

Grinder, R.E. (1989). Educational Psychology: the master science. In M.C. Witt rock, \& F. Farley (Eds.), The Future of Educational Psychology (pp.3-18). Hillsdale New Jersey: Lawrence Erlbaum Associates.

Kent, G.H., \& Rosanoff, A.J. (1910). A Study of Association in Insanity, I, Association in Normal Subjects. American Journal of Insanity, 67, 37-96 et 317-300.

Mercier Hugo, \& Sperber Dan. (2011). Why do humans reason? Arguments for an argumentative theory. Behavioral and Brain Sciences, 57-111. http://dx.doi.org/10.1017/S0140525X10000968

Sperber Dan, \& Wilson Deirdre. (1987). Précis of Relevance: Communication and Cognition. Behavioral and Brain Sciences, 697-754.

Welling, Hans. (2000, August). Four Mental Operations in Creative Cognition: The Importance of Abstraction. Creativity Research Journal, 163-177. http://dx.doi.org/10.1080/10400410701397214

\section{Copyrights}

Copyright for this article is retained by the author(s), with first publication rights granted to the journal.

This is an open-access article distributed under the terms and conditions of the Creative Commons Attribution license (http://creativecommons.org/licenses/by/4.0/). 